\title{
Benign prostatic hyperplasia and new treatment options - a critical appraisal of the UroLift system
}

This article was published in the following Dove Press journal:

Medical Devices: Evidence and Research

19 May 2016

Number of times this article has been viewed

\author{
Thomas Anthony \\ McNicholas ${ }^{1-3}$ \\ 'Section of Urology, Royal Society \\ of Medicine, London, UK; ${ }^{2}$ Urology \\ Department, Lister Hospital, East and \\ North Herts NHS Trust, Stevenage, \\ UK; ${ }^{3}$ Faculty of Health and Human \\ Sciences, University of Hertfordshire, \\ Hatfield, Herts, UK
}

\begin{abstract}
The prostatic urethral lift procedure, more commonly known as UroLift, has been designed to improve male lower urinary tract symptoms while avoiding the complications and disadvantages of existing drug and surgical therapies. In particular, UroLift does not damage ejaculatory function or affect orgasmic sensation. It appears an option for men who wish to avoid long-term drug therapy, the side effects of drugs or surgery and who do not need or will not accept traditional surgical treatments. UroLift was introduced following a series of planned studies that led to US Food and Drug Administration approval in September 2013. UroLift has recently been approved by the UK National Institute for Clinical and Health Excellence (September 2015) as effective and safe and cost-effective for use in the UK health system. This review describes the device and the procedure and the evidence base that has led to those approvals.
\end{abstract}

Keywords: UroLift, prostatic urethral lift, LUTS prostatic hyperplasia, minimally invasive, $\mathrm{BPH}$

\section{Introduction}

Male lower urinary tract symptoms (LUTS) are common and bothersome. Until the 1970 s, the only option was invasive surgery by open or endoscopic removal of the enlarged central prostatic tissue that was presumed to be the cause of the obstruction that in turn led to the symptoms. Many men were naturally anxious to avoid the side effects and complications of surgery such as bleeding, discomfort, a period of recovery, and the damaging effects on ejaculatory and orgasmic function that were almost inevitable with standard surgical treatments then and now. Since then, there has been a revolution in treatment, and many less severely bothered men now have the option of drug treatment to help their symptoms.

Nevertheless, many men are still dissatisfied with the treatment options available. Drug treatment does not work in many, or the side effects can be significant. Many men develop malaise and faintness, and most of the effective $\alpha$ blocker drugs will cause a variable degree of ejaculatory and orgasmic upset as well. Fundamentally, of course, many men do not welcome the need for long-term, indeed life long, drug treatment, which may affect their hormone balance (particularly with the other major drug treatment option 5- $\alpha$ reductase drugs to shrink the prostate) and their sexual function, as well as have an overall damaging impact on well-being and indeed their ability to work and to perform generally as they would wish.

Therefore, it appeared there was a need for an alternative treatment that would ideally be at least as effective as drug therapy and preferably more so, but with less

\footnotetext{
Correspondence:Thomas Anthony McNicholas

Elm Tree House, Letchworth Lane,

Letchworth, Herts SG6 3ND, UK

$\mathrm{Tel}+44 \mid 462683814$

Fax $+44 I 462683815$

Email mcnta@me.com
}

Medical Devices: Evidence and Research 2016:9 II5-123

I I5

Dovepress

http://dx.doi.org/10.2147/MDER.S60780 (c) (1) (5) 2016 McNicholas. This work is published and licensed by Dove Medical Press Limited. The full terms of this license are available at https://www.dovepress.com/terms.php cc) ${ }_{\mathrm{BY}} \mathrm{NC}$ and incorporate the Creative Commons Attribution - Non Commercial (unported, v3.0) License (http://creativecommons.org/licenses/by-n/3.0/). By accessing the work you hereby accept the Terms. Non-commercial uses of the work are permitted without any further permission from Dove Medical Press Limited, provided the work is properly attributed. For permission for commercial use of this work, please see paragraphs 4.2 and 5 of our Terms (https://www.dovepress.com/terms.php). 
A

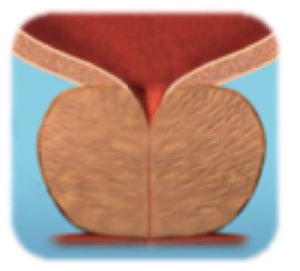

B

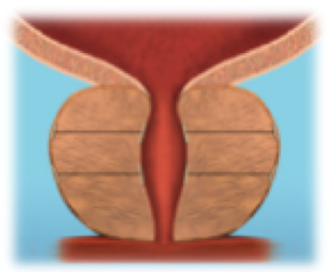

Figure I Applying a tissue retracting implant between the urethra and the prostatic capsule lifts the urethra toward the capsule thereby expanding the urethral lumen. Notes: Because the prostate capsule is firm, fibromuscular tissue and the glandular lobe tissue is compressible and sponge-like $(\mathbf{A})$, when the prostate wall is compressed, the urethra is lifted toward the outer capsule, and the capsule holds position. Thus, the prostatic urethra can be opened (B).

of the side effects and disadvantages of either drug treatment or the existing surgical treatment options.

In an ideal world, the approach would be novel, patentable, and protectable, and the procedure would be a day case or office-based one using minimal anesthesia or, ideally, local anesthetic alone.

A range of novel options were explored, and then the fundamental idea of the separation and distraction of the obstructing prostatic tissue by a series of implants was developed into the prototype device.

Basic laboratory-based work to define the tissue characteristics of the human male prostate was performed in the United States. Differences in the mechanical properties of the prostate tissues permit a mechanical deobstruction of the prostatic urethra. The urethra is compliant; the surrounding glandular tissue is compressible and sponge-like; and the fibromuscular outer prostatic capsule is tough. Thus, applying a tissue-retracting implant between the urethra and the prostatic capsule lifts the urethra toward the capsule, thereby expanding the urethral lumen (Figure 1). A prototype device was developed and was used in a pilot clinical study in Australia on males with urinary symptoms that suggested bladder outflow obstruction due to benign enlargement of the prostate.

A range of versions were further developed, and the final current version of the UroLift device and procedure that is in use today (Figure 2) has been studied in essentially all of the scientific studies published.

The idea is novel, and it was expected that it would take evidence and time to convince many urologists, so the device and procedure was developed with a planned series of rigorous scientific studies, which have been published in peer-reviewed journals (Table 1). The evidence accrued is considerable and led to FDA (US Food and Drug Administration) approval in September 2013 and NICE (National Institute for Clinical and Health Excellence) approval in the UK in February 2014. NICE, in September 2015, further approved UroLift as safe and effective and protective of male sexual function, but also as being cost-effective in a complex economic review. ${ }^{1}$ NICE recommended the device and the procedure for use in the UK National Health Service (NHS) health system as likely to save costs and to protect male sexual function. UroLift therefore has the distinction of being highly unusual in the field of urinary device treatments in that it has been introduced into clinical practice with evidence of safety and efficacy rather than being introduced and sold before such evidence had been accumulated.

\section{The UroLift device}

The UroLift ${ }^{\circledR}$ implant (NeoTract Inc., Pleasanton, CA, USA) is a permanent implant consisting of a nitinol capsular tab

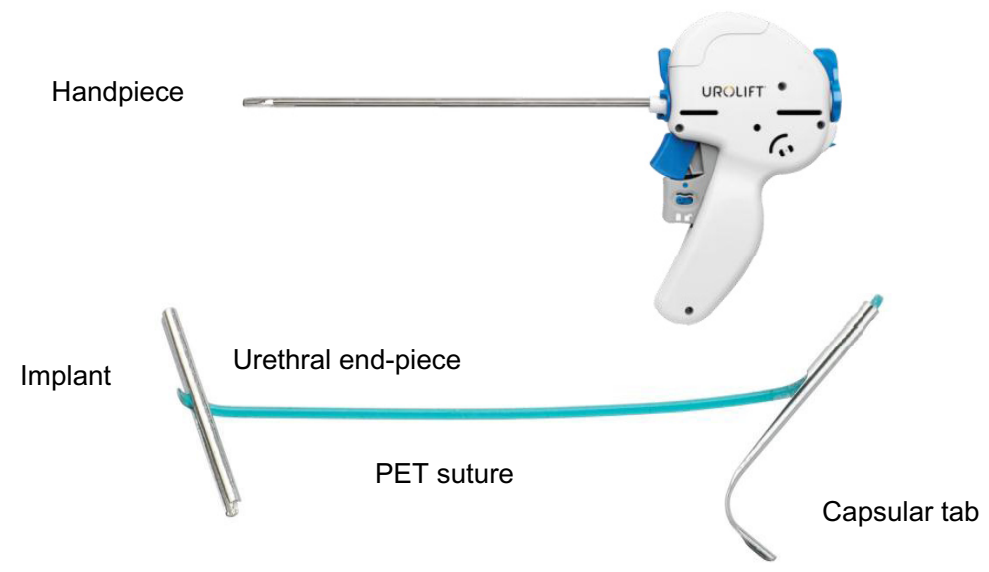

Figure 2 UroLift ${ }^{\circledR}$ system handpiece and implant.

Notes: The handpiece is passed under vision down the urethra and into the prostatic channel. The lateral prostatic lobes are separated to open the channel and fixed in the operator's chosen position by firing the handpiece mechanism that delivers an implant. The implant consists of: an urethral end piece made of surgical steel; a capsular tab made of nitinol; and a length of suture made of PET. During the procedure, the suture is cut to a customized length by the handpiece under the direction of the surgeon. Abbreviation: PET, polyethylene terephthalate. 
(0.6 mm diameter $\times 8 \mathrm{~mm}$ long), a stainless steel urethral end piece $(8 \mathrm{~mm} \times 1 \mathrm{~mm} \times 0.5 \mathrm{~mm})$, and an adjustable length of polyethylene teraphthalate (PET) monofilament $(0.4 \mathrm{~mm}$ diameter) between them (Figure 2). The UroLift system is a delivery device preloaded with the implant components and contains a spring-driven 19-gauge needle to traverse the prostatic lobe. The system is designed to: 1) deliver the implant to the desired anatomical location using cystoscopic guidance, 2) ensure delivery and attachment of the capsular tab onto the capsular surface, 3) customize the implant to the compressed lobe thickness at the point of delivery, and 4) allow the urethral end piece to invaginate into the urothelium, thereby "hiding" the implant from exposure to the urine stream and promoting rapid covering and epithelialization over the end piece. The polymeric PET monofilament component of the implant allows other interventions, including transurethral resection of the prostate (TURP) and laser treatments, if necessary in future.

\section{The prostatic urethral lift or "UroLift" procedure \\ Patient selection}

Careful patient selection is critical to ensuring a good clinical outcome. A realistic assessment of each man's treatment

Table I Scientific studies of UroLift published in peer-reviewed journals

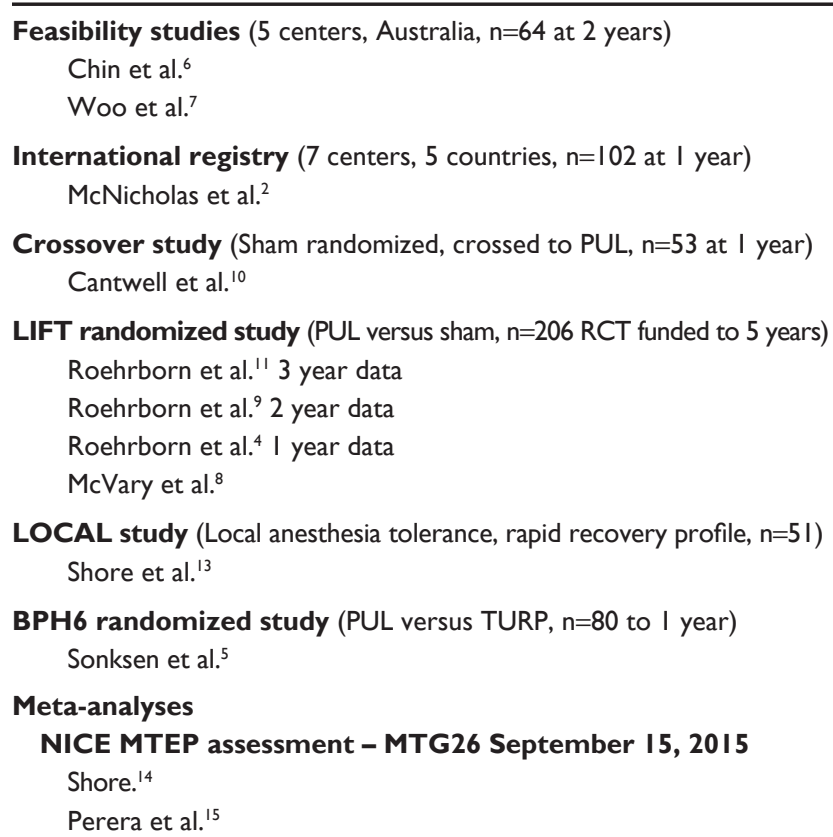

Abbreviations: PUL, prostatic urethral lift; LIFT, Long-Term Investigative Follow-Up in TrialNet; RCT, randomized controlled trial; LOCAL, UroLift system tOlerability and reCovery when Administering local Anesthesia; $\mathrm{BPH}$, benign prostatic hyperplasia; TURP, transurethral resection of the prostate; NICE, National Institute for Clinical and Health Excellence; MTEP, Medical Technologies Evaluation Programme; MTG26, Medical technology Guidance 26 goals is needed. First, men expecting the same dramatic improvement in flow and symptoms that follow TURP performed by an expert are likely to be disappointed. Those expecting no postoperative symptoms are being unrealistic. Evidence from the studies outlined in the "Clinical evidence" section and from increasing experience in more general urological use suggest minor bleeding and a temporary increase in urinary symptoms for 3-10 days that the potential patient should be aware of. However, men considering the UroLift procedure as a day case, ambulatory, or office-based treatment under intravenous sedation or even local anesthesia can expect a greater improvement in flow and symptoms than from the best drugs available and no interference with sexual function at the cost of minor, short-lived irritative symptoms and short-lived interference with life and work and a more rapid return to normal activities generally compared to the standard surgical treatments.

There are also technical and anatomical challenges in patient selection. Patients with a high bladder neck or a significant median or "middle" lobe are more challenging to treat and are not recommended until skilled in the technique. The device is not designed to address an obstructive middle lobe or prostates greater than $100 \mathrm{~g}$. Typical inclusion criteria are a prostate volume between 20 and $70 \mathrm{cc}$, urinary symptom score (such as the International Prostate Symptom Score or "IPSS") of 12 or greater, a measured maximal urinary flow $\left(Q_{\max }\right)$ of $15 \mathrm{~mL} / \mathrm{s}$ or less, and a measured postvoiding residual (PVR) urine of less than $350 \mathrm{~mL}$.

\section{Anesthesia}

The procedure has been performed under general, spinal, and local anesthesia with oral or intravenous sedation. For local anesthetic procedures, a bedside nurse helps to engage the patient, with the operator providing appropriate explanation during the procedure.

Direct visualization of the site of implant insertion is achieved using a $2.9 \mathrm{~mm} 0^{\circ}$ telescope (Storz Ref\# 10324A, Karl Storz GmbH \& Co, Tuttlingen, Germany), which is smaller than the standard telescope and gives a slightly smaller image than urologists are familiar with. The telescope is inserted through a compatible 20F cystoscopy sheath (Storz Ref \# 27027C, Karl Storz GmbH \& Co). The telescope can be used for telescopic examination of the prostate and bladder (known as cystoscopy) by means of a custom bridge (Storz Ref\# PV27025F-2, Karl Storz GmbH \& Co). The complete assembly is passed under direct vision by the surgeon. After inspection and assessment of suitable sites for implant insertion, the custom bridge is removed, the UroLift ${ }^{\circledR}$ handpiece (Figure 2) is inserted into the sheath, the telescope is inserted 
through the handpiece, and the tip of the handpiece is used to retract and compress the obstructing prostatic tissue under direct vision. Firing the triggers on the handpiece sequentially 1) fires a hollow needle through the prostate, 2) delivers the capsular element through the needle so it deploys and catches on the outer resisting tissue of the prostate, and 3) retracts the needle while maintaining tension on the suture. A separate trigger places the urethral element and cuts through the suture, thus positioning the implant in the desired position to fix the prostatic tissue so as to open the prostatic urethral lumen. Systematically, implants are delivered to both right and left lateral lobes of the prostate, working distally from approximately $1.5 \mathrm{~cm}$ distal to the bladder neck. The length of monofilament between the two metallic elements to be delivered at any one location is self-adjusted in situ by the tension and is essentially equal to the distance from the outer prostatic capsule to the inner urethral wall when compressed by the delivery device. Figure 3 shows endoscopic images of the male prostatic urethra before (above) and immediately after (below) insertion of UroLift implants. A more detailed description and accompanying instructional video is available. ${ }^{2}$

Generally, no catheter is required unless there has been bleeding or at the operator's discretion. The surgeon may judge a catheter to be necessary temporarily if there is likely to be severe obstruction already present or to overcome a short period of prostatic swelling as a result of the procedure. Most men will go home the same day with standard arrangements for review and follow-up. A short period of oral antibiotic cover and a supply of simple oral analgesics are usual.

Immediate removal of a device if inappropriately placed can be readily achieved with endoscopic graspers or biopsy forceps applied to the urethral end piece. The capsular element is left and the suture under tension retracts into the prostatic tissue. If complications develop later, such as inappropriate positioning with subsequent development of stone formation or if TURP or laser therapy is later thought necessary, then the devices can be easily removed by standard urological methods using a resectoscope or laser fiber to divide the suture and release the urethral end piece, which should be extracted.

\section{Clinical evidence}

UroLift has been assessed by a series of studies, using validated assessments and some novel outcome measurements (Table 1). Studies began with pilot studies of safety and to assess feasibility, ${ }^{3}$ recruited interested researchers to produce a Registry of experience, ${ }^{2}$ then progressed to the Luminal
Improvement Following Prostatic Tissue Approximation for the treatment of LUTS secondary to benign prostatic hyperplasia (BPH) or "Long-Term Investigative Follow-Up in TrialNet (LIFT)" study, ${ }^{4}$ a randomized multicenter sham comparison trial based largely in North America comparing the UroLift technique to a simple cystoscopy performed with similar sized instruments.

Subsequently there has been a randomized European multicenter trial of UroLift versus the most commonly used "gold standard" surgical treatment of TURP, and this is known as the BPH-6 study. ${ }^{5}$

The full range of studies has been recently reviewed in great detail by NICE as part of a formal technology review of effectiveness and cost-effectiveness to determine the potential role of UroLift in the NHS of the UK. ${ }^{1}$ Readers are recommended to consult this valuable, extensive, and independent assessment of UroLift.

Woo et $\mathrm{al}^{3}$ reported a case series of 19 patients in Australia with LUTS presumed to be due to BPH (mean prostate volume $=49 \mathrm{~cm}^{3}$ ) who underwent the UroLift system. The objective of the study was to assess the safety and efficacy of the technology. All procedures were performed successfully, with a postoperative catheterization rate of $58 \%$. Some minor side effects were reported (hematuria, dysuria, and irritation), but all resolved within a month. No retrograde ejaculation was reported. At 12-month follow-up, four patients had TURP. The authors noted that IPSS improvement was highest at 3 months after the UroLift procedure (57\% reduction). They also noted that there was no statistically significant change in maximal urinary flow (often reported as " $Q_{\max }$ ") or the volume of urine left behind after an attempt to empty the bladder (PVR).

Chin et $\mathrm{al}^{6}$ and Woo et $\mathrm{al}^{7}$ both reported on the same Australian multicenter study of 64 men (mean age $=66.9 \pm 7.3$ years, mean prostate volume $=51 \pm 23 \mathrm{~cm}^{3}$ ) with moderateto-severe LUTS. The authors also reported improvements following use of the UroLift system, using an average of four implants per procedure. At the 2-year follow-up, IPSS had decreased by $42 \%$ in the entire population $(95 \%$ confidence interval [CI], $-54 \%$ to $-31 \%$ ); at 3 years, some patients continued to show a $34 \%$ symptomatic improvement. Similar improvements were shown in the BPH Impact Index (BPHII) and quality of life (QoL) scores. Results were statistically significant for all of these outcomes at all time intervals. No decrease in sexual function was observed, and the validated ejaculatory function questionnaire (male sexual health questionnaire for ejaculatory dysfunction [MSHQEjD]) showed significant improvements at some intervals. 


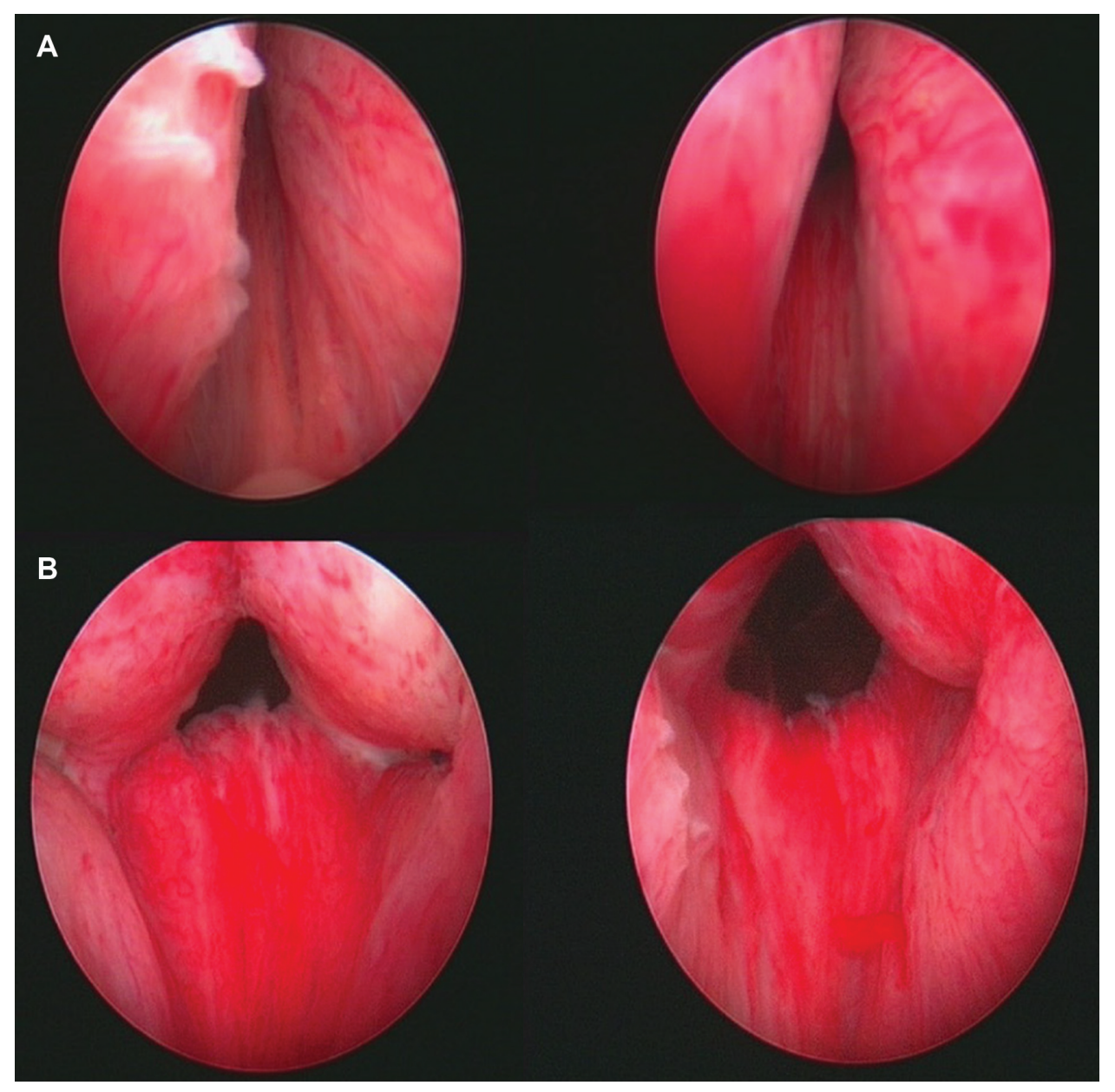

Figure 3 Images of male prostatic urethra before $(\mathbf{A})$ and immediately after $(\mathbf{B})$ insertion of UroLift implants.

Note: Image used with patient's permission.

Adverse events were minor, such as dysuria and hematuria, and typically resolved within 1 week. No blood transfusions were needed. Cystoscopic follow-up at 6 months $(n=22)$ showed no evidence of encrustation or infection. Postoperative catheterization rate was $53 \%$ (for a median of 20 hours). After 2 years, reoperation rate was $20 \%$ by either TURP, a repeat prostatic urethral lift (PUL), or photoselective laser vaporization of the prostate.

McNicholas et $\mathrm{al}^{2}$ reported the Registry study, an uncontrolled study of 102 men with LUTS (mean age $=68$ years, mean prostate size $=48 \mathrm{~cm}^{3}$, mean IPSS $=23.2$ ), which was done in seven centers across five countries. IPSS, QoL, BPHII, $Q \max$, and adverse event reports, including sexual function, were used as outcome measures. The authors reported that all procedures were completed successfully, with a mean of 4.5 implants per patient. Mean statistically significant improvements at 12 months were seen in IPSS (52\%), QoL (53\%), and $Q \max (51 \%)$. Adverse events were mild and transient, with no reported loss of antegrade ejaculation.
During the follow-up period, $6.5 \%$ of patients progressed to having TURP without complication. The authors noted the potential advantages of the UroLift system, including its minimally invasive nature, the avoidance of retrograde ejaculation, symptomatic improvement, and the fact that it could be performed under local anesthesia.

The LIFT study was a randomized controlled trial to evaluate the safety and effectiveness of the UroLift system. ${ }^{4}$ It was patient-blinded, and the comparator used was sham cystoscopy. The primary end point was IPSS reduction in the active arm at least $25 \%$ more than that in the control arm. The trial was conducted at 19 centers across the USA (14), Canada (2), and Australia (3) in men aged 50 years or older, with prostate volumes of $30-80 \mathrm{~cm}^{3}$ and an IPSS greater than 12. Patients were randomized $2: 1$ in favor of the intervention group, resulting in 140 men having the UroLift system and 66 having sham cystoscopy.

Roehrborn et al ${ }^{4}$ reported the results of the LIFT study and noted that the primary end point was met at 3 months. After 
12 months, IPSS, QoL score, $Q_{\max }$, and another validated questionnaire known as the BPHII score were all improved in patients who underwent UroLift insertion, compared with their baseline measurements.

McVary et $\mathrm{al}^{8}$ reported specifically on the preservation of sexual function in patients in the LIFT study and recorded sexual health outcome scores using the sexual health inventory for men (SHIM) and MSHQ-EjD. The results showed that using the UroLift system improved LUTS and urinary flow without compromising sexual function. There was no evidence of erectile or ejaculatory dysfunction in patients treated using the UroLift system. There was no difference in SHIM or MSHQ-EjD scores at 3 months compared with their baseline values, but these scores improved and were statistically significantly different from baseline after 1 year. An average of 4.9 UroLift implants was used per patient.

At the 2-year follow-up of the LIFT study cohort, Roehrborn et $\mathrm{al}^{9}$ reported a mean $42 \% \pm 7.6 \%$ decrease in IPSS ( $95 \%$ CI, $-48.5 \%$ to $-35.4 \%$ ) compared with baseline measurements. Similar improvements were also reported in BPHII score and QoL. Sexual health outcomes measured by SHIM and MSHQ-EjD scores indicated that improvements in sexual function were preserved throughout the second postoperative year. Within 2 years of first having the UroLift system, $7.5 \%$ of patients had a further procedure to treat LUTS; 5 had further UroLift implants and 5 had TURP or holmium laser enucleation of the prostate (HoLEP). All second procedures were done with no complications from the initial UroLift procedure.

Cantwell et a ${ }^{10}$ reported the subsequent use of the UroLift system in men who had been assigned to the control arm of the LIFT study. Of the 66 men who first had the sham procedure, $53(80 \%)$ chose further treatment with the UroLift system after unblinding (mean age $=68$ years, mean prostate volume $\left.=40.3 \mathrm{~cm}^{3}\right)$. Results showed that the UroLift system was statistically significantly more effective than the sham procedure, producing a mean reduction in IPSS at 12 months of $37 \%$ ( $95 \% \mathrm{CI},-46 \%$ to $-27 \%)$. The authors reported that sexual function was maintained, with no notable deterioration after use of the UroLift system; in fact, the UroLift system caused a statistically significant improvement in ejaculatory function at 3 months compared with sham procedure. Adverse events were reported as mild to moderate, and no blood transfusions were needed. The authors noted the symptomatic relief, low morbidity, and preservation of sexual function associated with the UroLift system.

Roehrborn et a ${ }^{11}$ reported 3-year follow-up results from the LIFT study. IPSS improvement was $43 \%$ after 3 years compared with patients who had sham $(P<0.0001)$. Fewer patients were reported at 3-year follow-up $(n=62)$ than at 2 years $(n=104)$, but the abstract did not describe reasons for dropouts at any time point. However, the results and adverse events remained consistent with those collected for the 2-year follow-up. Twelve subjects (8.6\%) had an apparently successful secondary procedure over the 3-year period.

Finally, Sonksen et $\mathrm{al}^{5}$ (Clinicaltrials.gov identifier: NCT01533038) reported a direct comparison of UroLift with TURP as part of a randomized, multicenter clinical trial based in European centers. They described outcomes in patients at 12 months and also introduced the concept of the "composite BPH-6 end point", which incorporated a range of outcomes likely to be of value to men seeking treatment for their LUTS over and above the expected improvement of symptoms and urinary flow (Table 2). Clearly, the "composite BPH-6 end point" needs to be further validated in future studies, but it does allow consideration of outcomes largely ignored in the literature of LUTS therapies so far. The NICE assessment group agreed that these end points were reasonable and justified and supported by the published literature.

Significant symptom relief was achieved in both treatment arms (Table 3). Both treatments significantly improved urinary flow rates but more so for TURP as expected (144\% versus $41 \%$ increase for UroLift). Significant improvements in IPSS, IPSS QoL, BPHII, and $Q_{\max }$ were observed in both arms over time. IPSS, $Q_{\max }$, and PVR were better after TURP than after PUL $(P<0.05)$. UroLift or PUL was found superior to TURP with respect to quality of recovery and preservation of ejaculatory function. The study demonstrated noninferiority for PUL, but also superiority of PUL over TURP on the BPH-6 end point. There were no statistically significant differences in baseline parameters except for the MSHQ-EjD function score. The UroLift arm experienced a significant improvement in MSHQ-EjD from baseline $(P=0.03)$, whereas the TURP arm experienced a significant deterioration $(P<0.0001)$. The UroLift system did not cause any adverse events that needed surgical intervention or revision, but further intervention was needed in two patients $(6 \%)$ in the TURP group. Patients having the UroLift system also experienced fewer treatment-related infections (7\%) than patients having TURP $(14 \% ; P=0.46)$.

PUL patients consistently had more rapid recovery than TURP patients. This study, perhaps for the first time, documents the pronounced delay to full recovery after surgical intervention by TURP for LUTS and suggests that it took men 6-12 months after TURP to recover to the same level achieved by 3 months for men after PUL. 
Table 2 The 6 elements of the BPH-6 end point

\begin{tabular}{|c|c|c|}
\hline BPH6 element & Assessment requirement & Rationale \\
\hline LUTS relief & $\begin{array}{l}\text { Reduction of } \geq 30 \% \text { in IPSS at } \\
12 \text { mo compared to baseline }\end{array}$ & $\begin{array}{l}\text { Analysis of large-scale randomized trials indicates that } 30 \% \text { IPSS improvement is } \\
\text { a suitable threshold for patient satisfaction and treatment acceptability }\end{array}$ \\
\hline Recovery experience & QoR VAS $\geq 70$ by I mo & $\begin{array}{l}\text { Postoperative return to normal activity is measured using a global QoR VAS } \\
\text { with significant convergent validity with the QoR score, a postoperative } \\
\text { recovery outcome with content and construct validity suitable for ambulatory } \\
\text { surgery. The threshold of } 70 \% \text { by I mo is chosen to reflect high-quality, rapid } \\
\text { recovery }\end{array}$ \\
\hline Erectile function & $\begin{array}{l}\text { Reduction of }<6 \text { points for SHIM } \\
\text { compared to baseline during } \\
12 \text { mo follow-up }\end{array}$ & $\begin{array}{l}\text { SHIM is widely used to measure the severity of erectile dysfunction in clinical } \\
\text { practice, and }>5 \text { points has been used as the minimum clinically meaningful } \\
\text { change }\end{array}$ \\
\hline Ejaculatory function & $\begin{array}{l}\text { Response to MSHQ-EjD question } \\
3 \text { indicating emission of semen } \\
\text { during } 12 \text { mo follow-up }\end{array}$ & $\begin{array}{l}\text { Absence of ejaculate has been quantified using the four-item MSHQ-EjD. } \\
\text { Postoperative emission of semen is indicated by a "nonzero" response to the } \\
\text { volume item of the questionnaire }\end{array}$ \\
\hline Continence preservation & $\begin{array}{l}\text { ISI score of } \leq 4 \text { points at all } \\
\text { follow-up intervals }\end{array}$ & $\begin{array}{l}\text { The ISI consists of two questions on the frequency and amount of urinary } \\
\text { leakage and bas been used in epidemiological surveys and clinical trials of LUTS } \\
\text { treatment. An incontinence threshold of ISI }>4 \text { corresponds to the threshold } \\
\text { for severe incontinence in the three-level index }\end{array}$ \\
\hline Safety & $\begin{array}{l}\text { No treatment-related adverse } \\
\text { event greater than grade I on the } \\
\text { Clavien-Dindo classification } \\
\text { system at any time during the } \\
\text { procedure or follow up }\end{array}$ & $\begin{array}{l}\text { The Clavien-Dindo classification of surgical complications has been validated in } \\
\text { many fields including urology. A threshold of grade II+ was selected to account } \\
\text { for events that might significantly affect a patient's postoperative course, such as } \\
\text { those requiring surgery, endoscopy, radiology, or supranormal pharmacology. If } \\
\text { a patient pursues secondary treatment, the failure to respond is captured in the } \\
\text { effectiveness element (\#I) and not the safety element (\#6); } \\
\text { the patient is therefore censored from the safety element analysis at all } \\
\text { subsequent time points }\end{array}$ \\
\hline
\end{tabular}

Note: Reproduced from Sonksen J, Barber NJ, Speakman MJ, et al. Prospective, randomized, multinational study of prostatic urethral lift versus transurethral resection of the prostate: 12-month results from the BPH6 study. Eur Urol. 2015;68(4):643-652. ${ }^{5}$

Abbreviations: BPH, benign prostatic hyperplasia; LUTS, lower urinary tract symptoms; IPSS, international prostate symptom score; QoR VAS, quality of recovery visual analog scale; SHIM, sexual health inventory for men, MSHQ-EjD, male sexual health questionnaire for ejaculatory dysfunction; ISI, incontinence severity index; mo, month.

Table 3 Outcomes of BPH-6: UroLift versus TURP randomized study

\begin{tabular}{llll}
\hline & PUL (\%) & TURP (\%) & P value \\
\hline $\begin{array}{l}Q_{\max } \\
\text { Composite primary endpoint }\end{array}$ & 41 & 144 & $<0.000$ I \\
\#I) LUTS & 52.3 & 20.0 & 0.005 \\
$\quad \begin{array}{l}(\geq 30 \% \text { IPSS reduction) } \\
\text { \#2) Recovery } \\
\quad(\geq 70 \% \text { VAS at I mo) }\end{array}$ & 72.7 & 91.2 & 0.05 \\
\#3) Erectile function \\
$\quad$ (<6 SHIM reduction)
\end{tabular}

Notes: Adapted from Sonksen J, Barber NJ, Speakman MJ, et al. Prospective, randomized, multinational study of prostatic urethral lift versus transurethral resection of the prostate: 12-month results from the BPH6 study. Eur Urol. 20I5;68(4):643-652. 80 men (45 UroLift: 35 TURP) followed to I year Primary endpoint met: BPH6 composite endpoint to reflect overall patient desires PUL superior to TURP, $P=0.005$.

Abbreviations: $\mathrm{BPH}$, benign prostatic hyperplasia;TURP, transurethral resection of the prostate; PUL, prostatic urethral lift; $Q_{m a x}$, maximal urinary flow; LUTS, lower urinary tract symptoms; IPSS, international prostate symptom score; VAS, visual analog scale; SHIM, sexual health inventory for men; MSHQ-EjD, male sexual health questionnaire for ejaculatory dysfunction; ISI, incontinence severity index; mo, month.

\section{Regulatory approvals}

The evidence accrued led to FDA approval in September 2013 and NICE approval in the UK in February 2014.

\section{Conclusion}

UroLift is the product of a search for a novel treatment method providing moderate improvement in men's LUTS that is sufficient for most men without the side effects of available surgery while producing more benefit than drug treatments. UroLift is an option for symptomatic men who do not wish for, or respond to, or cannot tolerate long-term drug therapy. Those men wishing to preserve sexual and especially ejaculatory function can confidently be offered UroLift as an alternative to surgical therapy.

It will not be appropriate for all men, especially those with unfavorable anatomy, such as men with very large prostates or those with a large "middle lobe".

An extensive and high-quality scientific literature is available. The timeline for the milestones of development of UroLift are shown in Figure 4. UroLift has the distinction of being highly unusual in the field of urinary device treatments in that it has been introduced into clinical practice with evidence of safety and efficacy rather than 
Prostatic urethral lift: progress to adoption

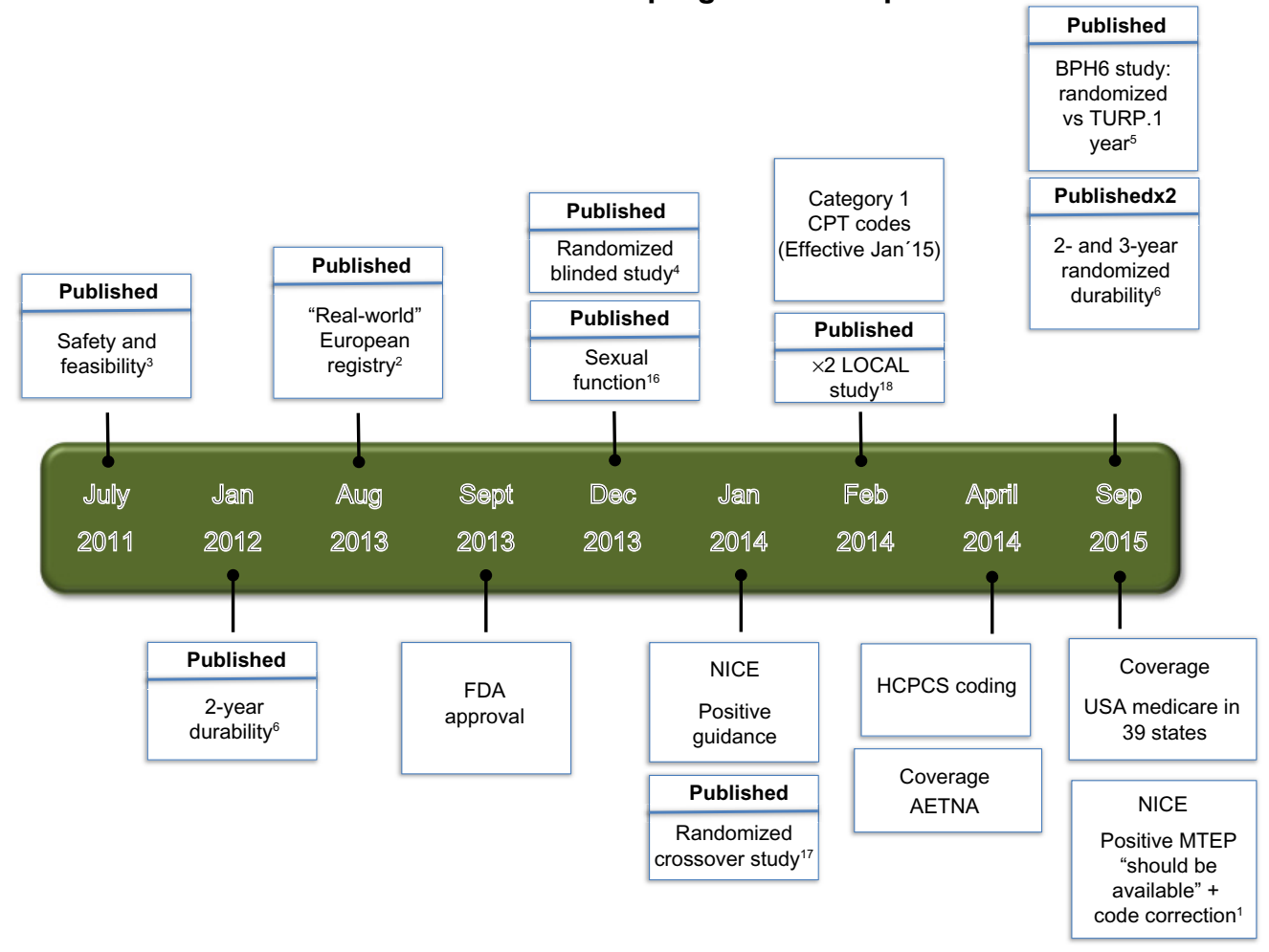

Figure 4 Timeline of UroLift milestones.

Abbreviations: BPH, benign prostatic hyperplasia; TURP, transurethral resection of the prostate; LOCAL, UroLift system tOlerability and reCovery when Administering Local Anesthesia; FDA, US Food and Drug Administration; NHS, National Health Service; NICE, National Institute for Clinical and Health Excellence; MTEP, Medical Technologies Evaluation Programme.

being introduced and sold before such evidence had been accumulated.

In September 2015, NICE further assessed the UroLift treatment method. In this detailed and publicly accessible review of the complete literature, the NICE assessors sought to compare outcomes for UroLift with standard available surgical methods, ie, TURP and HoLEP. ${ }^{1,12}$ As a result of favorable outcomes from this complex economic review, NICE approved UroLift not only as being safe and effective and protective of male sexual function but also as being costeffective. ${ }^{1}$ NICE recommended the device and the procedure for use in the UK NHS health system as likely to save costs and to protect male sexual function.

\section{Disclosure}

The author has been an advisor to Neotract since 2005 and has been paid for advisory work and for mentoring new users of UroLift. The author reports no other conflicts of interest in this work.

\section{References}

1. NICE. UroLift for treating lower urinary tract symptoms of benign prostatic hyperplasia. Available from: nice.org.uk/guidance/mtg26. 2015;mtg26. Accessed February 16, 2016.
2. McNicholas TA, Woo HH, Chin PT, et al. Minimally invasive prostatic urethral lift: surgical technique and multinational experience. Eur Urol. 2013;64(2):292-299.

3. Woo HH, Chin PT, McNicholas TA, et al. Safety and feasibility of the prostatic urethral lift: a novel, minimally invasive treatment for lower urinary tract symptoms (LUTS) secondary to benign prostatic hyperplasia (BPH). BJU Int. 2011;108(1):82-88.

4. Roehrborn CG, Gange SN, Shore ND, et al. The prostatic urethral lift for the treatment of lower urinary tract symptoms associated with prostate enlargement due to benign prostatic hyperplasia: the L.I.F.T. study. J Urol. 2013;190(6):2161-2167.

5. Sonksen J, Barber NJ, Speakman MJ, et al. Prospective, randomized, multinational study of prostatic urethral lift versus transurethral resection of the prostate: 12-month results from the BPH6 study. Eur Urol. 2015;68(4):643-652.

6. Chin PT, Bolton DM, Jack G, et al. Prostatic urethral lift: two-year results after treatment for lower urinary tract symptoms secondary to benign prostatic hyperplasia. Urology. 2012;79(1):5-11.

7. Woo HH, Bolton DM, Laborde E, et al. Preservation of sexual function with the prostatic urethral lift: a novel treatment for lower urinary tract symptoms secondary to benign prostatic hyperplasia. J Sex Med. 2012;9(2):568-575.

8. McVary KT, Gange SN, Shore ND, et al. Treatment of LUTS secondary to BPH while preserving sexual function: randomized controlled study of prostatic urethral lift. J Sex Med. 2014;11(1):279-287.

9. Roehrborn C, Gange S, Shore N, et al. Durability of the prostatic urethral lift: 2-year results of the L.I.F.T. study. Urol Pract. 2015;2: 26-32.

10. Cantwell AL, Bogache WK, Richardson SF, et al. Multicentre prospective crossover study of the 'prostatic urethral lift' for the treatment of lower urinary tract symptoms secondary to benign prostatic hyperplasia. BJU Int. 2014;113(4):615-622. 
11. Roehrborn C, Rukstalis DB, Barkin J, et al. Three year results of the prostatic urethral LIFT study. Can J Urol. 2015;22(3):7772-7782.

12. NICE. UroLift for treating lower urinary tract symptoms of benign prostatic hyperplasia. 2015. Available from: http://www.nice.org.uk/ guidance/mtg26/resources/urolift-for-treating-lower-urinary-tractsymptoms-of-benign-prostatic-hyperplasia-64371938204869. Accessed November 12, 2015.

13. Shore N, Freedman S, Gange S, et al. Prospective multi-center study elucidating patient experience after prostatic urethral lift. Can J Urol. 2014;21(1):7094-7101.

14. Shore N. A Review of the Prostatic Urethral Lift for Lower Urinary Tract Symptoms: Symptom Relief, Flow Improvement, and Preservation of Sexual Function in Men With Benign Prostatic Hyperplasia. Curr Bladder Dysfunct Rep. 2015;10(2):186-192.

15. Perera M, Roberts MJ, Doi SA, Bolton D. Prostatic urethral lift improves urinary symptoms and flow while preserving sexual function for men with benign prostatic hyperplasia: a systematic review and metaanalysis. Eur Urol. 2015;67(4):704-713.
16. McVary KT, Gange SN, Shore ND, et al. Treatment of LUTS secondary to $\mathrm{BPH}$ while preserving sexual function: randomized controlled study of prostatic urethral lift. The journal of sexual medicine. 2014;11(1):279-287.

17. Cantwell AL, Bogache WK, Richardson SF, et al. Multicentre prospective crossover study of the 'prostatic urethral lift' for the treatment of lower urinary tract symptoms secondary to benign prostatic hyperplasia. BJU international. 2014;113(4):615-622.

18. Shore N, Freedman S, Gange S,(17) et al. Prospective multi-center study elucidating patient experience after prostatic urethral lift. Can J Urol. 2014;21(1):7094-7101.

\section{Publish your work in this journal}

Medical Devices: Evidence and Research is an international, peerreviewed, open access journal that focuses on the evidence, technology, research, and expert opinion supporting the use and application of medical devices in the diagnosis, treatment and management of clinical conditions and physiological processes. The identification of novel devices and optimal use of existing devices which will lead to improved clinical outcomes and more effective patient management and safety is a key feature. The manuscript management system is completely online and includes a quick and fair peer-review system. Visit http://www. dovepress.com/testimonials.php to read real quotes from authors.

Submit your manuscript here: http://www.dovepress.com/medical-devices-evidence-and-research-journal 